\title{
Porphyria cutanea tarda in a HIV- positive patient ${ }^{*}$
}

\author{
Valéria Aparecida Zanela Franzon ${ }^{1,2}$ \\ Fernanda Henriques Camelo ${ }^{1}$
}

\author{
Emanuella Stella Mikilita ${ }^{1}$ \\ Rosana Camargo ${ }^{1,3}$
}

DOI: http://dx.doi.org/10.1590/abd1806-4841.20163808

\begin{abstract}
This is a case report about Porphyria cutanea tarda (PCT) and its relationship with the infection caused by the human immunodeficiency virus (HIV). Cutaneous porphyria is an illness caused by enzymatic modification that results in partial deficiency of uroporphyrinogen decarboxylase (Urod), which may be hereditary or acquired. Several studies suggest that HIV infection associated with cofactors might trigger the development of porphyria cutanea tarda. In this case report, we present a patient infected with HIV, who after the introduction of antiretroviral therapy (ART) enjoyed clinical improvement of porphyria cutanea tarda symptoms.
\end{abstract}

Keywords: Porphyria cutanea tarda; HIV; Risk factors

\section{INTRODUCTION}

Porphyrias are rare metabolic disorders which are characterized by an abnormality in the biosynthesis of heme complex by erythrocytes, due to an enzymatic deficiency in the production of porphyrin precursors. ${ }^{1-3}$

They can divided into four types, according to their characteristics. The sporadic form (Type I), also named "acquired", is characterized by a decreased hepatic activity of uroporphyrinogen decarboxylase (Urod) while the disease is active. The hereditary form of porphyria cutanea tarda (PCT) (Type II) is a dominant autosomal disease with genetic mutations of the Urod gene and is associated with family history. The toxic form of PCT (Type III) is characterized by its sporadic nature. The hepatoerythropoietic form of porphyria (Type IV) is caused by a homozygotic defect of Urod. The clinical courses are very similar. ${ }^{4}$

PCT usually affects middle-aged individuals, over 40 years old. ${ }^{1}$ The disease has as main triggering factors: alcohol, iron, estrogen, hepatitis $\mathrm{C}$ virus ( $\mathrm{HCV})$, human immunodeficiency virus (HIV), polychlorinated hydrocarbons and hemodialysis/chronic renal failure $(\mathrm{CRF}) .^{3,5}$

The interest in reporting this PCT case is based on the rarity of the disease and questioning HIV as the only triggering factor.

\section{Received on 30.06.2014.}

Approved by the Advisory Board and accepted for publication on 13.01.2015.

Work performed at Pontifícia Universidade Católica do Paraná and at Hospital Oswaldo Cruz - Curitiba (PR), Brazil.

Financial Support: None.

Conflict of Interest: None.

Pontifícia Universidade Católica do Paraná (PUCPR) - Curitiba (PR), Brazil.

Fundação Pró-Hansen - Curitiba (PR), Brazil.

Hospital Oswaldo Cruz - Curitiba (PR), Brazil. 


\section{CASE REPORT}

Male patient, 54 years old, white and merchant, had been infected with HIV for approximately 20 years. He underwent several antiretroviral therapies (ART), nevertheless in 2012 he abandoned treatment. In the beginning of 2013, he presented vesicular and bullous lesions, with citrine yellow content, on the back of hands, upper limbs and face (Figure 1). In photoexposed areas, he presented hyperpigmentation, erosions, miliary and atrophic scars. In February $8^{\text {th }}, 2013$ tests revealed CD4 count $=24$ cells $/ \mathrm{mm}, \mathrm{CD} 8=853$ cells $/ \mathrm{mm}$ and viral load $=4,439$ copies $/ \mathrm{ml}$ (b-DNA technique).

He reported tuberculosis, cryptococcal meningitis, pneumocystic pneumonia, esophageal candidiasis and renal failure (by tenofovir).

In lab tests, liver biochemistry showed TGP $=101 \mathrm{U} / \mathrm{L}$, $\mathrm{TGO}=44 \mathrm{U} / \mathrm{L}$ and GGT $=127 \mathrm{U} / \mathrm{L}$. Serological tests for hepatitis B and $\mathrm{C}$ were not reagent.

Uroporphyrinogen dosage in the urine was negative, which may have occurred due to delay in the analysis of the urine or inadequate collection. However, urine fluorescence test with Wood's lamp was positive. The patient was taken to a dermatology clinic where he was guided to collect his urine. His urine was immediately analyzed in a dark room with a Wood's lamp along with the urine from the lab staff. It presented a faint reddish-pink fluorescence, confirming the presence of uroporphyrins (Figure 2). Anatomopathological examination showed, in a lesser magnification, skin with subepidermal blister, dermal papillae preserved on the site of epidermal detachment and, in the dermis, a minimal inflammatory perivascular lymphocytic infiltrate (Figure 3). With greater augmentation hyaline material deposited around blood vessels was revealed, which is consistent with a diagnosis of PCT. The situation evolved to clinical improvement after reinstating ART with lamivudine (150 mg every 12 hours), didanosine (400 mg / day) and atazanavir (200 mg / day) (Figure 4).

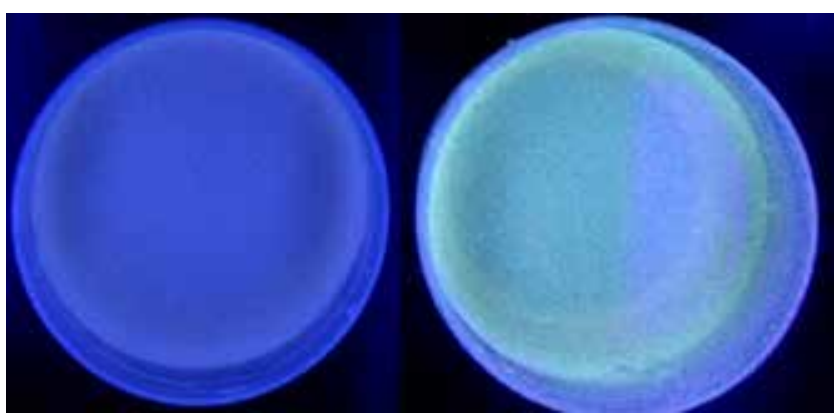

FIGURE 2: Urine fluorescence test with Wood lamp. The test on the right is the patient's, which presented a faint reddish-pink fluorescence, confirming the presence of uroporphyrin. The one on the left shows the examiner's urine (control)

\section{DISCUSSION}

Porphyrias are metabolic disorders characterized by an abnormality in the biosynthesis of heme complex by erythrocytes, caused by deficiency of the Urod enzyme. With that, porphyrins uroporphyrin and 7-carboxyl-porphyrinogen - are cumulative, and may be excreted in the urine and feces or deposited in various tissues throughout the body. ${ }^{1-4}$

The deposition of porphyrins in the skin causes cutaneous photo-sensitization, because they are unable to store energy from light, which is released to the skin as a photochemical reaction, causing cutaneous damage. ${ }^{3,4}$

Clinical manifestations are: skin fragility, vesicles and bullae (tense, with hyaline content), followed by erosion and crusts, which occur mainly in areas exposed to the sun and trauma areas, such as face and back of hands and feet. Hyperpigmentation of areas exposed to the sun may occur. There can still be hypertrichosis,
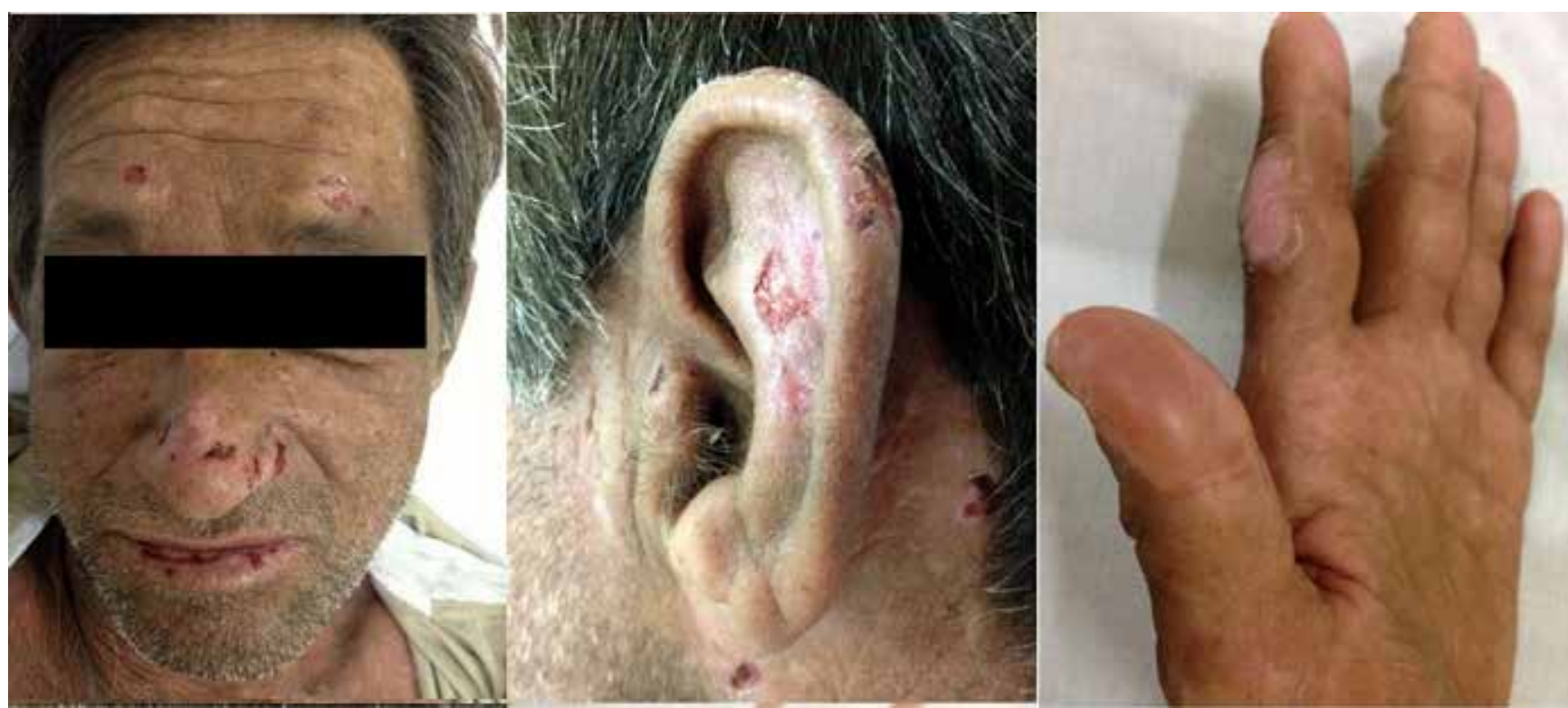

FIGURE 1: Ulcerated lesions and miliary atrophic scars on the nose, lips and forehead region. Ulcerated ruptured bullae on the pinna and bullae with citrine yellow content on the fingers 


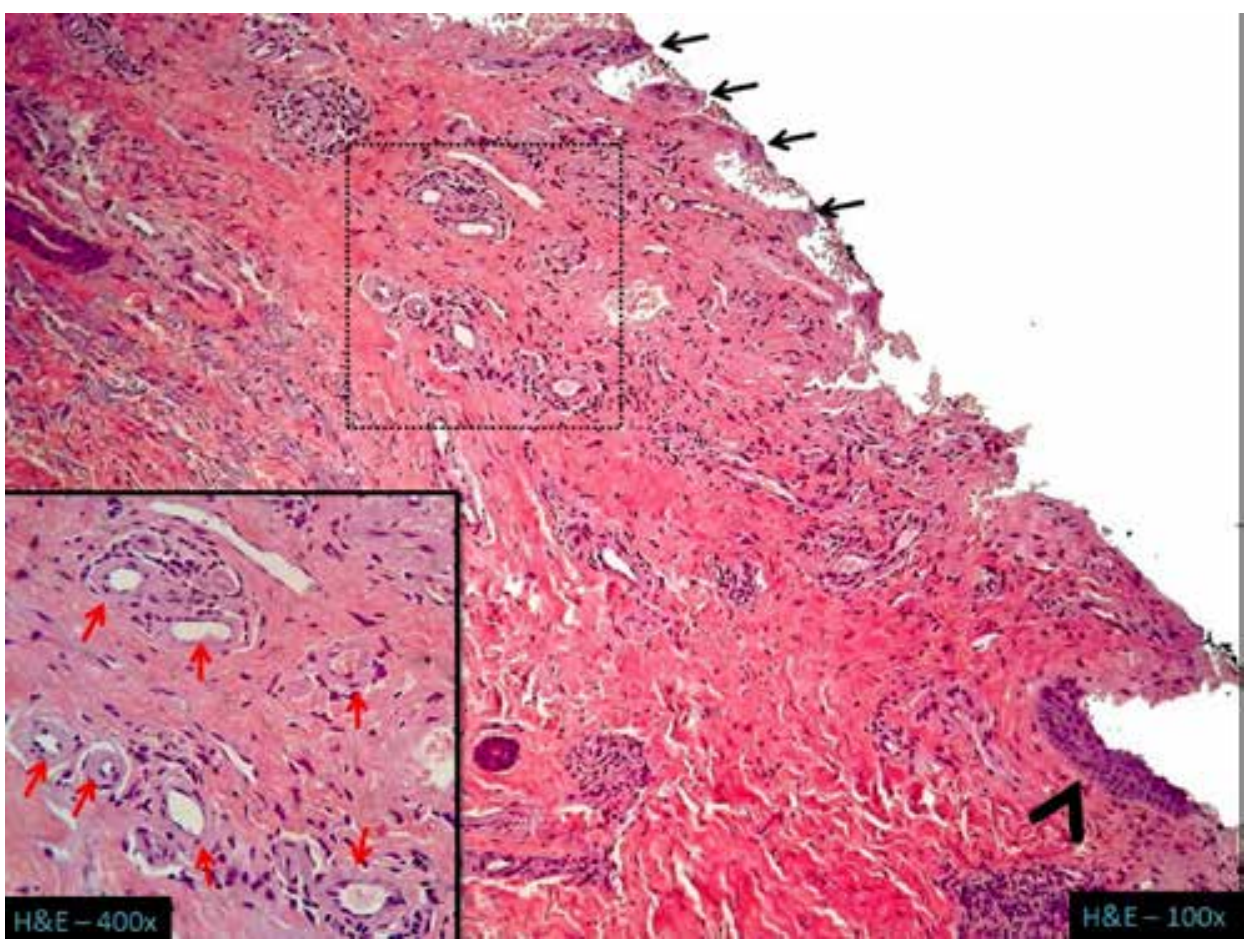

FiguRE 3:

Anatomopathological examination of cutaneous lesions. In a lesser augmentation, skin with subepidermal blister (arrow's head), preserved dermal papillae at the site of epidermal detachment (black arrows) and, in the dermis, a minimal inflammatory perivascular lymphocytic infiltrate. In the detail, in a great augmentation, hyaline material deposited around blood vessels (red arrows)
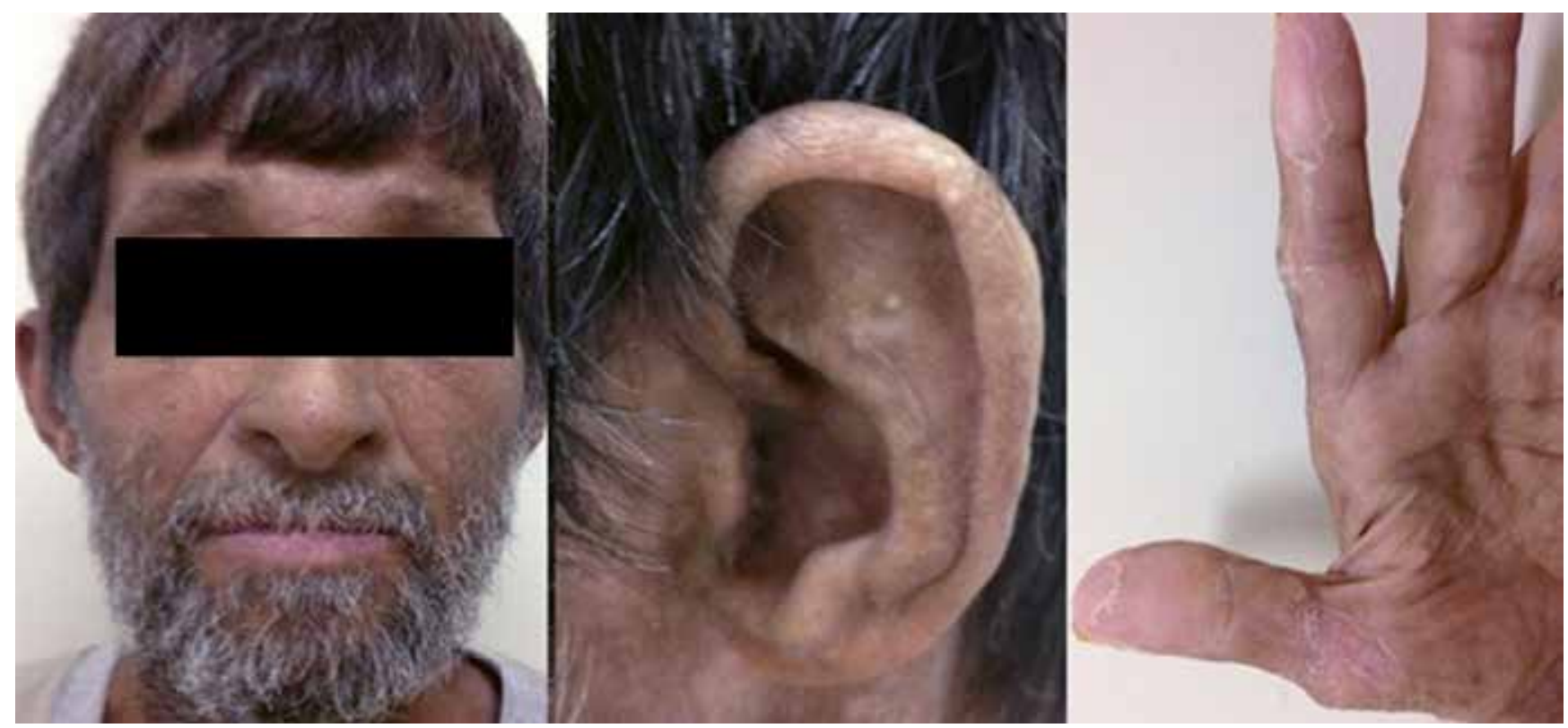

Figure 4: Clinical aspect after reintroduction of ART. Remission of bullous lesions and reepithelialization of nose, pinna and hand, with areas of hypochromia

sclerodermoid plaques, scarring alopecia, premature aging, solar elastosis and onycholysis. Systemic manifestations are: peripheral neuropathy, palmar fibromatosis, hearing loss, insomnia, personality disorders, conjunctivitis, nausea, anorexia, diarrhea and constipation. $^{3}$
The association of HIV with PCT was initially acknowledged in 1987. There are cases reported in which PCT starts in the primary phases of the infection and others in which the development of PCT is late. In most of the reports, there is association of risk factors, suggesting that the combination of these factors causes 
hepatic lesions and that HIV infection makes them worse. ${ }^{1,3}$ However, there are reports describing the development of PCT in patients who presented infection by HIV as the single risk factor. ${ }^{1,6-8}$

The risk factors are: alcohol, hereditary hemochromatosis, estrogen, HCV, HIV, polychlorinated hydrocarbons, chronic renal failure and smoking. ${ }^{3-5}$

The physiopathology of PCT and HIV association is not totally understood, however the authors suggest that HIV carriers have altered steroid metabolism, which increases the production of endogenous estrogen and, consequently, interferes in the synthesis of heme, causing PCT. HIV infection is the cause of abnormal excretion of porphyrins, even with no clinical evidence of PCT. ${ }^{1,9}$

Some studies suggest that PCT may be caused by ART., On the other hand, other studies report improvement of patients after the start of ART. ${ }^{7,10}$

Treatment consists of identification and elimination of the causing factor. Phlebotomy could be performed weekly, collecting $500 \mathrm{ml}$ per session, until hemoglobin reaches a level lower than 10 $\mathrm{g} / \mathrm{dl}$, or serum iron reaches $50 \mathrm{~g} / \mathrm{dl}$ to $60 \mathrm{~g} / \mathrm{dl}$ or less, or even porphyrins in the urine reach a level lower than $400 \mu \mathrm{g}$. Oral chloroquine therapy is also used, twice a week, at low doses (125 mg to $250 \mathrm{mg}$ ). Cimetidine is also described as a therapeutic option for PCT, at $800 \mathrm{mg} /$ day. $^{3}$

HIV may play an independent role in causing PCT. Of all known risk factors, HIV was the only one present in the reported case. After the reintroduction and correct use of ART (its use was irregular), there was clinical remission of the disease, which also suggests that HIV and high levels of viral replication may be direct inducers of PCT. $\square$

\section{ACKNOWLEDGMENTS}

We would like to specially thank the pathology service of Hospital das Clínicas de Curitiba and physician Ricardo Hohmann Camiña, who performed the anatomopathological tests and supplied photographs of the slides used in this study.

\title{
REFERENCES
}

1. Conde Almeida AC, Villa RT, Bedin V. Porfiria cutânea tarda no paciente infectado pelo vírus da imunodeficiência adquirida. Med Cutan Iber Lat Am. 2010;38:91-3.

2. Elder GH, Roberts AG. Uroporphyrinogen decarboxylase. J Bioenerg Biomembr. 1995;27:207-14

3. Vieira FMJ, Martins JEC. Porfiria Cutânea Tardia. An Bras Dermatol. 2006;81:57384.

4. Bernardes Filho F, Santos MV, Carvalho FN, Castro CG, Dobao E, Lyra MR, et al HAART: a risk factor for development of porphyria cutanea tarda? Rev Soc Bras Med Trop. 2012;45:764-7.

5. Egger NG, Goeger DE, Payne DA, Miskovsky EP, Weinman SA, Anderson KE, et al. Porphyria cutanea tarda: multiplicity of risk factors including HFE mutations, hepatitis C, and inherited uroporphyrinogen decarboxylase deficiency. Dig Dis Sci. 2002;47:419-26.

6. Celesia BM, Onorante A, Nunnari G, Mughini MT, Mavilla S, Massimino SD, et al. Porphyria cutânea tarda in an HIV-1-infected patient after the initiation of tipranavir/ ritonavir: case report. AIDS. 2007;21:1495-6.

7. Gafà S, Zannini A, Gabrielli C. Porphyria cutanea tarda and HIV Infection: Effect of Zidovudine Treatment on a Patient. Infection. 1992;20:373-4.

8. Hassoun A, Corman L, Ibrahim F. An HIV-Infected Woman With Porphyria Cutanea Tarda. AIDS Read. 2008;18:271-2.

9. Vasconcelos P, Luz-Rodrigues H, Santos C, Filipe P. Desferrioxamine treatment of porphyria cutanea tarda in a patient with HIV and chronic renal failure. Dermatol Ther. 2014;27:16-8.

10. Rich JD, Mylonakis E, Nossa R, Chapnick RM. Highly Active Antiretroviral Therapy Leading to Resolution of Porphyria Cutanea Tarda in a Patient with AIDS and Hepatitis C. Digestive Dig Dis Sci. 1999;44:1034-7.

\author{
MAILING ADDRESS: \\ Emanuella Stella Mikilita \\ Rua Brigadeiro Franco, 1.491, ap. 702 \\ Centro \\ 80420-200 - Curitiba - PR \\ Brazil \\ E-mail:manu.miki@hotmail.com
}

How to cite this article: Franzon VAZ, Mikilita ES, Camelo FH, Camargo R. Porphyria Cutanea Tarda in a patient HIV positive. An Bras Dermatol. 2016;91(4):520-3. 